\title{
Convergence of a hybrid iterative method for finite families of generalized quasi- $\phi$-asymptotically nonexpansive mappings
}

Bashir Ali ${ }^{* *}$ and MS Minjibir ${ }^{2}$

"Correspondence:

bashiralik@yahoo.com

'Department of Mathematical

Sciences, Bayero University, Kano, Nigeria

Full list of author information is

available at the end of the article

\begin{abstract}
Strong convergence theorem for finite families of generalized quasi- $\phi$-asymptotically nonexpansive mappings is proved in a real uniformly convex and uniformly smooth Banach space using a new modified hybrid iterative algorithm.

MSC: 47H09; 47J25

Keywords: generalized quasi- $\phi$-asymptotically nonexpansive mappings; generalized projection map; hybrid methods; uniformly convex Banach space; uniformly smooth Banach space
\end{abstract}

\section{Introduction}

Let $E$ be a real Banach space and $E^{*}$ be the dual space of $E$. The normalized duality mapping $J: E \rightarrow 2^{E^{*}}$ is defined by

$$
J x=\left\{x^{*} \in E^{*}:\left\langle x, x^{*}\right\rangle=\|x\|\left\|x^{*}\right\|,\left\|x^{*}\right\|=\|x\|\right\}
$$

for all $x \in E$, where $\langle\cdot, \cdot\rangle$ denotes the duality pairing. A Banach space $E$ is said to be uniformly convex if given $\epsilon \in(0,2]$, there exists $\delta>0$ such that for all $x, y \in E$ with $\|x\| \leq 1$, $\|y\| \leq 1$ and $\|x-y\| \geq \epsilon$, we have $\left\|\frac{x+y}{2}\right\| \leq 1-\delta$. E is strictly convex if $\left\|\frac{x+y}{2}\right\|<1$ for all $x, y \in E$ with $\|x\|=\|y\|=1$ and $x \neq y$. The space $E$ is said to be smooth if the limit

$$
\lim _{t \rightarrow 0} \frac{\|x+t y\|-\|x\|}{t}
$$

exists for all $x, y \in U$, where $U:=\{z \in E:\|z\|=1\}$. It is also uniformly smooth if the limit exists uniformly for $x, y \in U$. It is well known that if $E$ is strictly convex, smooth and reflexive, then the duality map $J$ is one-to-one, single-valued and onto. Also if $E$ is uniformly smooth, then $J$ is norm-to-norm uniformly continuous on bounded subsets of $E$.

Let $C$ be a nonempty, closed, convex subset of $E$. Let $T: C \rightarrow C$ be a map, a point $x \in C$ is called a fixed point of $T$ if $T x=x$ and the set of all fixed points of $T$ is denoted by $F(T)$. We recall that a point $p \in C$ is called an asymptotic fixed point of $T$ if there exists a sequence $\left\{x_{n}\right\} \subset C$ which converges weakly to $p$ and $\lim _{n \rightarrow \infty}\left\|x_{n}-T x_{n}\right\|=0$. The mapping 
$T$ is called Lipschitz if there exists $L>0$ such that $\|T x-T y\| \leq L\|x-y\|$ for all $x, y \in C$, and if $L=1$, then $T$ is called nonexpansive. $T$ is asymptotically nonexpansive if there exists a sequence $\left\{t_{n}\right\} \subset[1, \infty)$ such that $t_{n} \rightarrow 1$ as $n \rightarrow \infty$ and $\left\|T^{n} x-T^{n} y\right\| \leq t_{n}\|x-y\|$ for all $n \in \mathbb{N}$ and for all $x, y \in C$. The map $T$ is quasi-nonexpansive if $F(T) \neq \emptyset$ and for all $x \in C$, $q \in F(T),\|T x-q\| \leq\|x-q\|$ and is called asymptotically quasi-nonexpansive if $F(T) \neq \emptyset$ and $\left\|T^{n} x-q\right\| \leq t_{n}\|x-q\|$ for all $x \in C, q \in F(T)$ and the sequence $\left\{t_{n}\right\} \subset[1, \infty)$ satisfies $t_{n} \rightarrow 1$ as $n \rightarrow \infty$. The mapping $T$ is called generalized asymptotically quasi-nonexpansive if $F(T) \neq \emptyset$, there exist sequences $\left\{s_{n}\right\} \subset[0,1],\left\{t_{n}\right\} \subset[1, \infty)$ with $s_{n} \rightarrow 0, t_{n} \rightarrow 1$ as $n \rightarrow \infty$ and $\left\|T^{n} x-q\right\| \leq t_{n}\|x-q\|+s_{n}$ for all $x \in C, q \in F(T)$ and $n \in \mathbb{N}$.

The map $T$ is said to be

(i) asymptotically regular on $C$ if $\lim _{n \rightarrow \infty}\left\|T^{n+1} x-T^{n} x\right\|=0$ for all $x \in C$,

(ii) uniformly asymptotically regular on $C$ if $\lim _{\sup _{n \rightarrow \infty x \in K}}\left\|T^{n+1} x-T^{n} x\right\|=0$ holds for any bounded subset $K$ of $C$.

For a positive real number $L$, the map $T$ is called uniformly L-Lipschitzian if $\left\|T^{n} x-T^{n} y\right\| \leq$ $L\|x-y\|$ for all $x, y \in C$ and $n \in \mathbb{N}$.

It is clear from these definitions that every nonexpansive mapping with a fixed point is quasi-nonexpansive and all asymptotically nonexpansive maps with fixed points are asymptotically quasi-nonexpansive. Recently, the class of generalized asymptotically quasi-nonexpansive mappings was introduced and studied by Shahzad and Zegeye [21]. They proved that every asymptotically quasi-nonexpansive mapping is a generalized asymptotically quasi-nonexpansive mapping and the inclusion is proper. The class of quasi-nonexpansive mappings was introduced and studied first in 1967 by Diaz and Metcalf [7]. Goebel and Kirk [8] introduced the class of asymptotically nonexpansive mappings and proved that if $C$ is a nonempty, closed, convex and bounded subset of a uniformly convex Banach space $E$, then an asymptotically nonexpansive mapping $T: C \rightarrow C$ has a fixed point.

Kirk [16], proved that if $E$ is a reflexive Banach space with normal structure and $C$ is a nonempty, closed, convex and bounded subset of $E$, a nonexpansive map $T: C \rightarrow C$ has a fixed point in $C$. This result was extended to a finite family of nonexpansive maps by Bellus and Kirk [3] and then to an infinite family of nonexpansive maps by Lim [17].

Let $H$ be a real Hilbert space, $C$ be a nonempty closed convex subset of $H$. Recall that for each $x \in H$ there exists a unique nearest point in $C$ to $x$ denoted by $P_{C} x$. That is, $\| x-$ $P_{C} x\|\leq\| x-y \|$ for all $y \in C$. $P_{C}$ is called a metric projection of $H$ onto $C$.

It is well known that the metric projection is nonexpansive only in a Hilbert space. This fact actually characterizes Hilbert spaces. Alber [1], introduced a generalized projection map $\prod_{C}: E \rightarrow C$ in a Banach space which is an analogue of the metric projection in a Hilbert space.

Let $E$ be a real normed linear space with single-valued normalized duality map. Consider the functional defined by $\phi(x, y)=\|x\|^{2}+\|y\|^{2}-2\langle x, J y\rangle$. We observe that in a Hilbert space, $\phi(x, y)$ reduces to $\|x-y\|^{2}$. It is clear that for $x, y \in E$, the following inequality holds ( $\|x\|-$ $\|y\|)^{2} \leq \phi(x, y) \leq(\|x\|+\|y\|)^{2}$. The generalized projection map $\prod_{C}: E \rightarrow C$ is a map that assigns to an arbitrary point $x \in E$, the minimum point of the functional $\phi(x, \cdot)$ over $C$, that is, $\prod_{C} x=x^{*}$ where $\phi\left(x, x^{*}\right)=\min _{y \in C} \phi(x, y)$. Existence and uniqueness of the map $\prod_{C}$ follow from the properties of the functional $\phi$ and the strict monotonicity of $J$ (see, for example, [2]). 
Let $C$ be a nonempty, closed, and convex subset of $E$, a mapping $T: C \rightarrow C$ is said to be

(i) relatively nonexpansive if $F(T)=\widetilde{F(T)}$ and $\phi(q, T x) \leq \phi(q, x)$ for all $x \in C, q \in F(T)$ where $\widetilde{F(T)}$ denotes the set of asymptotic fixed points of $T$;

(ii) $\phi$-nonexpansive if $\phi(T x, T y) \leq \phi(x, y)$ for all $x, y \in C$;

(iii) $\phi$-asymptotically nonexpansive if there exists a sequence $\left\{t_{n}\right\} \subset[1, \infty)$ satisfying $t_{n} \rightarrow \infty$ as $n \rightarrow \infty$ and $\phi\left(T^{n} x, T^{n} y\right) \leq t_{n} \phi(x, y)$ for all $x, y \in C, n \in \mathbb{N}$;

(iv) quasi- $\phi$-asymptotically nonexpansive if $F(T) \neq \emptyset$ and $\phi\left(q, T^{n} x\right) \leq t_{n} \phi(q, x)$ for all $x \in C, q \in F(T), n \in \mathbb{N}$, where $\left\{t_{n}\right\}$ is as in (iii) above.

We shall call the map $T$ generalized quasi- $\phi$-asymptotically nonexpansive in the light of [21], if $F(T) \neq \emptyset$ and there exist sequences $\left\{s_{n}\right\} \subset[0,1],\left\{t_{n}\right\} \subset[1, \infty)$ with $s_{n} \rightarrow 0, t_{n} \rightarrow 1$ as $n \rightarrow \infty$ and $\phi\left(q, T^{n} x\right) \leq t_{n} \phi(q, x)+s_{n}$ for all $x \in C, q \in F(T)$ and $n \in \mathbb{N}$.

Existence and approximations of fixed points of mappings of nonexpansive type and their generalizations were studied by numerous authors, see, for example, $[3,5,7,8,10$, $11,14-17,19,21,27$ ] and the references therein.

In 1986, Das and Debata [6] studied the Ishikawa-like scheme defined by $x_{1} \in C$,

$$
x_{n+1}=\alpha_{n} S\left[\beta_{n} T x_{n}+\left(1-\beta_{n}\right) x_{n}\right]+\left(1-\alpha_{n}\right) x_{n},
$$

where $\left\{\alpha_{n}\right\}$ and $\left\{\beta_{n}\right\}$ are sequences in $[a, b]$ such that $0<a<b<1$. They studied the scheme for two quasi-nonexpansive maps $S$ and $T$ and proved strong convergence of the sequence $\left\{x_{n}\right\}$ to a common fixed point of $S$ and $T$ in a real strictly convex Banach space. Takahashi and Tamura [25] proved strong and weak convergence of the sequence defined by (1.1) to a common fixed point of a pair of nonexpansive mappings $T$ and $S$ using a weaker condition on the maps.

Using a similar scheme, Wang [26] proved strong and weak convergence theorems for a pair of nonselfasymptotically nonexpansive mappings in a uniformly convex Banach space.

Shahzad and Udomene [22] proved the necessary and sufficient conditions for the strong convergence of the scheme of type (1.1) to a common fixed point of two uniformly continuous asymptotically quasi-nonexpansive mappings in a real Banach space.

Chidume and Ali [4] introduced and proved strong convergence of the scheme defined by

$$
\left\{\begin{array}{l}
x_{1} \in C, \\
x_{n+1}=P\left[\left(1-\alpha_{1 n}\right) x_{n}+\alpha_{1 n} T_{1}\left(P T_{1}\right)^{n-1} y_{n+m-2}\right], \\
y_{n+m-2}=P\left[\left(1-\alpha_{2 n}\right) x_{n}+\alpha_{2 n} T_{2}\left(P T_{2}\right)^{n-1} y_{n+m-3}\right], \\
\vdots \\
y_{n}=P\left[\left(1-\alpha_{m n}\right) x_{n}+\alpha_{m n} T_{m}\left(P T_{m}\right)^{n-1} x_{n}\right], \quad n \geq 1
\end{array}\right.
$$

to a common fixed point of a finite family of nonself asymptotically nonexpansive mappings in a uniformly convex Banach space. 
Khan et al. [13] introduced and studied the following scheme:

$$
\left\{\begin{array}{l}
x_{1} \in K, \quad y_{0 n}=x_{n} \\
x_{n+1}=\left(1-\alpha_{k n}\right) x_{n}+\alpha_{k n} T_{k}^{n} y_{k-1 n} \\
y_{k-1 n}=\left(1-\alpha_{k-1 n}\right) x_{n}+\alpha_{k-1 n} T_{k-1}^{n} y_{k-2 n} \\
\vdots \\
y_{1 n}=\left(1-\alpha_{1 n}\right) x_{n}+\alpha_{1 n} T_{1}^{n} y_{0 n}, \quad n \geq 1
\end{array}\right.
$$

for a common fixed point of a finite family of asymptotically quasi-nonexpansive mappings in a Banach space.

It is known that only weak convergence theorems were proved for nonexpansive maps even in Hilbert spaces using Mann and Ishikawa type schemes.

In 2000 Solodov and Svaiter [23] introduced a hybrid proximal point type iterative scheme and proved the strong convergence of the scheme to a zero of a maximal monotone operator.

In 2003 Nakajo and Takahashi [19] proposed a hybrid Mann scheme for nonexpansive mappings and nonexpansive semigroups and proved strong convergence theorems.

Kim and $\mathrm{Xu}$ [14] generalized the result of Nakajo and Takahashi by proving strong convergence theorems for asymptotically nonexpansive mappings and asymptotically nonexpansive semigroups. Plubtieng and Ughchittrakool [20] introduced an Ishikawa type hybrid scheme for two asymptotically nonexpansive mappings and two asymptotically nonexpansive semigroups.

Takahashi et al. [24] studied a simpler hybrid scheme for nonexpansive mappings in Hilbert spaces. Inchan and Plubtieng [10], adopted this simpler scheme of Takahashi et al. with little modification for two nonexpansive maps and two nonexpansive semigroups. They proved the following theorem:

Theorem 1.1 ([10]) Let $H$ be a real Hilbert space and let $C$ be a nonempty, closed, convex, and bounded subset of $H$. Let $S, T: C \rightarrow C$ be two asymptotically nonexpansive mappings with sequences $\left\{s_{n}\right\}$ and $\left\{t_{n}\right\}$ respectively and $F=F(S) \cap F(T) \neq \emptyset$. Let $x_{0} \in C$. Then the sequence $\left\{x_{n}\right\}$ generated by

$$
\left\{\begin{array}{l}
y_{n}=\alpha_{n} x_{n}+\left(1-\alpha_{n}\right) T_{1}^{n} z_{n}, \\
z_{n}=\beta_{n} x_{n}+\left(1-\beta_{n}\right) S^{n} x_{n}, \\
C_{n+1}=\left\{z \in C_{n}:\left\|y_{n}-z\right\|^{2} \leq\left\|x_{n}-z\right\|^{2}+\theta_{n}\right\} \\
x_{n+1}=P_{C_{n+1}} x_{0}, \quad n \in \mathbb{N}
\end{array}\right.
$$

converges strongly to $z_{0}=P_{F} x_{0}$, where $\theta_{n}=\left(1-\alpha_{n}\right)\left[\left(t_{n}^{2}-1\right)+\left(1-\beta_{n}\right) t_{n}^{2}\left(s_{n}^{2}-1\right)\right](\operatorname{diam} C)^{2} \rightarrow 0$ as $n \rightarrow \infty$ and $0 \leq \alpha_{n} \leq a<1,0<b \leq \beta_{n} \leq c<1$ for all $n \in \mathbb{N}$.

Kimura and Takahashi [15] proved strong convergence theorem for the family of relatively nonexpansive mappings in strictly convex Banach spaces having Kadec-Klee property and Frechet differentiable norm.

Recently, Zhou et al. [28] have proved strong convergence theorem for the family $T_{i}$ : $C \rightarrow C, i \in I$ of quasi- $\phi$-asymptotically nonexpansive mappings, where $C$ is a nonempty, 
closed, convex and bounded subset of a uniformly smooth and uniformly convex Banach space $E$.

More recently, Xu et al. [27] have studied a modified hybrid scheme for fixed point of families of quasi- $\phi$-asymptotically nonexpansive mappings. They proved the following theorem:

Theorem 1.2 ([27]) Let $C$ be a nonempty closed convex subset of a uniformly convex and uniformly smooth Banach space $E$, and let $T_{i}: C \rightarrow C, i \in I$ be a family of closed and quasi$\phi$-asymptotically nonexpansive mappings such that $F:=\bigcap_{i \in I} F\left(T_{i}\right) \neq \emptyset$. Assume that every $T_{i}, i \in I$ is asymptotically regular on $C$. Let $\left\{\alpha_{n}\right\},\left\{\beta_{n}\right\}$ and $\left\{\gamma_{n}\right\}$ be real sequences in $[0,1]$ such that $\lim _{n \rightarrow \infty} \alpha_{n}=0, \liminf _{n \rightarrow \infty} \gamma_{n}>0$. Define a sequence $\left\{x_{n}\right\}$ in $C$ by:

$$
\left\{\begin{array}{l}
x_{0} \in C \quad \text { chosen arbitrarily, } \\
y_{n i}=j^{-1}\left(\alpha_{n} j x_{0}+\beta_{n} j x_{n}+\gamma_{n} j T_{i}^{n} x_{n}\right), \\
C_{0}=C, \\
C_{n, i}=\left\{z \in C_{n-1}: \phi\left(z, y_{n, i}\right) \leq \alpha_{n} \phi\left(z, x_{0}\right)+\left(\beta_{n}+\gamma_{n} k_{n, i}\right) \phi\left(z, x_{n}\right)\right\}, \\
C_{n}=\bigcap_{i \in I} C_{n, i}, \\
x_{n+1}=\prod_{C_{n}} x_{0} .
\end{array}\right.
$$

Then, $\left\{x_{n}\right\}$ converges strongly to $\prod_{F} x_{0}$, where $\prod_{F}$ is the generalized projection from $E$ onto $F$.

Motivated by these results, we have the purpose in this paper to study a new modified hybrid iterative scheme and prove a strong convergence theorem for a finite family of generalized quasi- $\phi$-asymptotically nonexpansive mappings in a uniformly convex and uniformly smooth real Banach space. Our theorems improve and unify several recent important results.

\section{Preliminaries}

Consider a sequence $\left\{C_{n}\right\}$ of nonempty closed and convex subsets of a reflexive Banach space $E$. Let $s-\lim C_{n}$ denotes the set of all strong limits of sequences $\left\{x_{n}\right\}$ satisfying $x_{n} \in$ $C_{n}$ for all $n \in \mathbb{N}$ and $w-\lim C_{n}$ be the set of all weak limits of sequences $\left\{y_{i}\right\}$ satisfying $y_{i} \in C_{n_{i}}$ for all $i \in \mathbb{N}$ where $\left\{C_{n_{i}}\right\}$ is some subsequence of $\left\{C_{n}\right\}$. The sequence $\left\{C_{n}\right\}$ is said to converge to $C^{*}$ in the sense of Mosco [18] if $s-\lim C_{n}=w-\lim C_{n}=C^{\prime \prime}$. The Mosco limit of $\left\{C_{n}\right\}$ is denoted by $M-\lim C_{n}$.

We shall make use of the following important results in the sequel.

Lemma 2.1 (Kamimura and Takahashi [12]) Let E be a real smooth and uniformly convex Banach space and $\left\{x_{n}\right\},\left\{y_{n}\right\}$ be two sequences of $E$. If $\lim _{n \rightarrow \infty} \phi\left(x_{n}, y_{n}\right)=0$ and either $\left\{x_{n}\right\}$ or $\left\{y_{n}\right\}$ is bounded, then $\lim _{n \rightarrow \infty}\left\|x_{n}-y_{n}\right\|=0$.

Lemma 2.2 (Ibaraki, Kimura and Takahashi [9]) Let C be a nonempty closed convex subset of a real uniformly smooth and uniformly convex Banach space $E$. Let $\left\{C_{n}\right\}$ be a sequence of nonempty closed convex subsets of $C$. If $M-\lim C_{n}=C^{*}$ exists and is nonempty, then $\left\{\prod_{C_{n}} x\right\}$ converges strongly to $\left\{\prod_{C^{*}} x\right\}$ for each $x \in E$. 
The result in [9] is more general than the one presented here, but this is sufficient for our purpose.

Lemma 2.3 Let $C$ be a nonempty closed convex subset of a real smooth Banach space and $T: C \rightarrow C$ be a closed generalized quasi- $\phi$-asymptotically nonexpansive mapping. Then $F(T)$ is closed and convex.

Proof By the closedness assumption on $T$ and the definition of $\phi$, the result follows immediately.

\section{Main results}

Theorem 3.1 Let E be a real uniformly convex and uniformly smooth Banach space and $C$ be a nonempty, bounded, closed and convex subset of $E$. Let $T_{k}: C \rightarrow C, k=1,2,3, \ldots, m$ be a finite family of closed generalized quasi- $\phi$-asymptotically nonexpansive maps with corresponding sequences $\left\{t_{k n}\right\}$ and $\left\{s_{k n}\right\}, k=1,2,3, \ldots, m$ such that $t_{k n} \rightarrow 1$ and $s_{k n} \rightarrow 0$ as $n \rightarrow \infty$. Let $F=\bigcap_{k=1}^{m} F\left(T_{k}\right) \neq \emptyset$ and let $t_{n}=\max _{1 \leq k \leq m} t_{k n}, n \in \mathbb{N}$. Assume also that the maps $T_{k}, k=1,2, \ldots, m$ are uniformly asymptotically regular. Let $x_{0} \in C$ be arbitrary and $C_{0}=C$ and let $M=\sup _{x, y \in C} \phi(x, y)$. For $k=1,2, \ldots, m$, let $\left\{\beta_{k n}\right\}$ be sequences in $(a, b)$ for some $a, b \in(0,1), a<b$. Let $\left\{x_{n}\right\}$ be a sequence generated by

$$
\left\{\begin{array}{l}
x_{1}=x_{0}, \\
z_{1 n}=j^{-1}\left(\beta_{1 n} j x_{n}+\left(1-\beta_{1 n}\right) j T_{1}^{n} x_{n}\right), \\
z_{k n}=j^{-1}\left(\beta_{k n} j x_{n}+\left(1-\beta_{k n}\right) j T_{k}^{n} z_{(k-1) n}\right), \quad k=2,3,4, \ldots, m, \\
C_{k n}=\left\{v \in C_{n-1}: \phi\left(v, z_{k n}\right) \leq \phi\left(v, x_{n}\right)+\gamma_{k n}\right\}, \quad k=1,2,3, \ldots, m, \\
C_{n}=\bigcap_{k=1}^{m} C_{k n}, \\
x_{n+1}=\prod_{C_{n}} x_{0}, \quad n \geq 1,
\end{array}\right.
$$

where $\gamma_{k n}=\left(t_{n}-1\right)\left(1-\beta_{k n}\right)\left[1+t_{k n}\left(1-\beta_{(k-1) n}\right)\left[1+t_{(k-1) n}\left(1-\beta_{(k-2) n}\right) \times\left[1+t_{(k-2) n}(1-\right.\right.\right.$ $\left.\left.\left.\left.\beta_{(k-3) n}\right)\left[\cdots\left[1+t_{2 n}\left(1-\beta_{1 n}\right)\right] \cdots\right]\right]\right]\right] M+\sum_{i=1}^{k} s_{i n} \prod_{j=i}^{k}\left(1-\beta_{j n}\right) \prod_{l=i+1}^{k} t_{l n}$. Then the sequence $\left\{x_{n}\right\}$ converges strongly to $x^{*}=\prod_{F} x_{0}$.

Proof We start by showing that $F \subset C_{n} \forall n \in \mathbb{N} \cup\{0\}$. We do this by induction. $F \subset C_{0}$ by definition. We suppose that $F \subset C_{N}$ for some $N \in \mathbb{N} \cup\{0\}$. We observe that for $v \in F$, using convexity of $\|\cdot\|^{2}$ and (3.1), we have

$$
\begin{aligned}
\phi\left(v, z_{1 n}\right)= & \|v\|^{2}+\left\|j^{-1}\left(\beta_{1 n} j x_{n}+\left(1-\beta_{1 n}\right) j T_{1}^{n} x_{n}\right)\right\|^{2} \\
& -2\left\langle v, j\left(j^{-1}\left(\beta_{1 n} j x_{n}+\left(1-\beta_{1 n}\right) j T_{1}^{n} x_{n}\right)\right)\right\rangle \\
= & \beta_{1 n}\|v\|^{2}+\left(1-\beta_{1 n}\right)\|v\|^{2}+\left\|\beta_{1 n} j x_{n}+\left(1-\beta_{1 n}\right) j T_{1}^{n} x_{n}\right\|^{2} \\
& -2\left\langle v, \beta_{1 n} j x_{n}+\left(1-\beta_{1 n}\right) j T_{1}^{n} x_{n}\right\rangle \\
\leq & \beta_{1 n}\left(\|v\|^{2}+\left\|x_{n}\right\|^{2}-2\left\langle v, j x_{n}\right\rangle\right) \\
& +\left(1-\beta_{1 n}\right)\left(\|v\|^{2}+\left\|j T_{1}^{n} x_{n}\right\|^{2}-2\left\langle v, j T_{1}^{n} x_{n}\right\rangle\right) \\
= & \beta_{1 n} \phi\left(v, x_{n}\right)+\left(1-\beta_{1 n}\right) \phi\left(v, T_{1}^{n} x_{n}\right) \\
\leq & \phi\left(v, x_{n}\right)-\left(1-\beta_{1 n}\right) \phi\left(v, x_{n}\right)+\left(1-\beta_{1 n}\right) t_{1 n} \phi\left(v, x_{n}\right)+\left(1-\beta_{1 n}\right) s_{1 n}
\end{aligned}
$$




$$
\begin{aligned}
& =\phi\left(v, x_{n}\right)+\left(t_{1 n}-1\right)\left(1-\beta_{1 n}\right) \phi\left(v, x_{n}\right)+s_{1 n}\left(1-\beta_{1 n}\right) \\
& \leq \phi\left(v, x_{n}\right)+\left(t_{n}-1\right)\left(1-\beta_{1 n}\right) \phi\left(v, x_{n}\right)+s_{1 n}\left(1-\beta_{1 n}\right)
\end{aligned}
$$

and

$$
\begin{aligned}
\phi\left(v, z_{2 n}\right)= & \|v\|^{2}+\left\|j^{-1}\left(\beta_{2 n} j x_{n}+\left(1-\beta_{2 n}\right) j T_{2}^{n} z_{1 n}\right)\right\|^{2} \\
& -2\left\langle v, j\left(j^{-1}\left(\beta_{2 n} j x_{n}+\left(1-\beta_{2 n}\right) j T_{2}^{n} z_{1 n}\right)\right)\right\rangle \\
\leq & \phi\left(v, x_{n}\right)-\left(1-\beta_{2 n}\right) \phi\left(v, x_{n}\right)+\left(1-\beta_{2 n}\right) t_{2 n} \phi\left(v, z_{1 n}\right)+\left(1-\beta_{2 n}\right) s_{2 n} \\
\leq & \phi\left(v, x_{n}\right)-\left(1-\beta_{2 n}\right) \phi\left(v, x_{n}\right) \\
& +\left(1-\beta_{2 n}\right) t_{2 n}\left[\phi\left(v, x_{n}\right)+\left(t_{n}-1\right)\left(1-\beta_{1 n}\right) \phi\left(v, x_{n}\right)+\left(1-\beta_{1 n}\right) s_{1 n}\right] \\
& +\left(1-\beta_{2 n}\right) s_{2 n} \\
= & \phi\left(v, x_{n}\right)+\left(t_{2 n}-1\right)\left(1-\beta_{2 n}\right) \phi\left(v, x_{n}\right)+\left(1-\beta_{2 n}\right) t_{2 n}\left[\left(t_{n}-1\right)\left(1-\beta_{1 n}\right) \phi\left(v, x_{n}\right)\right] \\
& +\left(1-\beta_{1 n}\right)\left(1-\beta_{2 n}\right) s_{1 n} t_{2 n}+\left(1-\beta_{2 n}\right) s_{2 n} \\
\leq & \phi\left(v, x_{n}\right)+\left(t_{n}-1\right)\left(1-\beta_{2 n}\right)\left[1+t_{2 n}\left(1-\beta_{1 n}\right)\right] \phi\left(v, x_{n}\right) \\
& +s_{1 n}\left(1-\beta_{1 n}\right)\left(1-\beta_{2 n}\right) t_{2 n}+s_{2 n}\left(1-\beta_{2 n}\right) .
\end{aligned}
$$

Similarly,

$$
\begin{aligned}
\phi\left(v, z_{3 n}\right)= & \|v\|^{2}+\left\|j^{-1}\left(\beta_{3 n} j x_{n}+\left(1-\beta_{3 n}\right) j T_{3}^{n} z_{2 n}\right)\right\|^{2} \\
& -2\left\langle v, j\left(j^{-1}\left(\beta_{3 n} j x_{n}+\left(1-\beta_{3 n}\right) j T_{3}^{n} z_{2 n}\right)\right)\right\rangle \\
\leq & \phi\left(v, x_{n}\right)-\left(1-\beta_{3 n}\right) \phi\left(v, x_{n}\right)+\left(1-\beta_{3 n}\right) t_{3 n} \phi\left(v, z_{2 n}\right)+\left(1-\beta_{3 n}\right) s_{3 n} \\
\leq & \phi\left(v, x_{n}\right)-\left(1-\beta_{3 n}\right) \phi\left(v, x_{n}\right) \\
& +\left(1-\beta_{3 n}\right) t_{3 n}\left[\phi\left(v, x_{n}\right)+\left(t_{n}-1\right)\left(1-\beta_{2 n}\right)\left[1+t_{2 n}\left(1-\beta_{1 n}\right)\right] \phi\left(v, x_{n}\right)\right. \\
& \left.+\left(1-\beta_{1 n}\right)\left(1-\beta_{2 n}\right) s_{1 n} t_{2 n}+\left(1-\beta_{2 n}\right) s_{2 n}\right]+\left(1-\beta_{3 n}\right) s_{3 n} \\
\leq & \phi\left(v, x_{n}\right)+\left(t_{n}-1\right)\left(1-\beta_{3 n}\right) \phi\left(v, x_{n}\right) \\
& +\left(1-\beta_{3 n}\right) t_{3 n}\left[\left(t_{n}-1\right)\left(1-\beta_{2 n}\right)\left[1+t_{2 n}\left(1-\beta_{1 n}\right)\right]\right] \phi\left(v, x_{n}\right) \\
& +s_{1 n}\left(1-\beta_{1 n}\right)\left(1-\beta_{2 n}\right)\left(1-\beta_{3 n}\right) t_{2 n} t_{3 n}+s_{2 n}\left(1-\beta_{2 n}\right)\left(1-\beta_{3 n}\right) t_{3 n}+s_{3 n}\left(1-\beta_{3 n}\right) \\
= & \phi\left(v, x_{n}\right)+\left(t_{n}-1\right)\left(1-\beta_{3 n}\right)\left[1+t_{3 n}\left(1-\beta_{2 n}\right)\left[1+t_{2 n}\left(1-\beta_{1 n}\right)\right]\right] \phi\left(v, x_{n}\right) \\
& +\sum_{i=1}^{3} s_{i n} \prod_{j=i}^{3}\left(1-\beta_{j n}\right) \prod_{l=i+1}^{3} t_{l n} .
\end{aligned}
$$

Continuing in this way, we get for $k=4,5, \ldots, m$,

$$
\begin{aligned}
\phi\left(v, z_{k n}\right) \leq & \phi\left(v, x_{n}\right)+\left(t_{n}-1\right)\left(1-\beta_{k n}\right)\left[1+t_{k n}\left(1-\beta_{(k-1) n}\right)\right. \\
& \times\left[1+t_{(k-1) n}\left(1-\beta_{(k-2) n}\right)\left[1+t_{(k-2) n}\left(1-\beta_{(k-3) n}\right)\right.\right. \\
& \left.\left.\left.\times\left[\cdots\left[1+t_{2 n}\left(1-\beta_{1 n}\right)\right] \cdots\right]\right]\right]\right] M
\end{aligned}
$$




$$
\begin{aligned}
& +\sum_{i=1}^{k} s_{i n} \prod_{j=i}^{k}\left(1-\beta_{j n}\right) \prod_{l=i+1}^{k} t_{l n} \\
= & \phi\left(v, x_{n}\right)+\gamma_{k n} .
\end{aligned}
$$

So $\phi\left(v, z_{k(N+1)}\right) \leq \phi\left(v, x_{N+1}\right)+\gamma_{k(N+1)}$ for any $v \in F$ and $k \in\{1,2, \ldots, m\}$. This and the induction hypothesis give that $F \subset C_{k(N+1)}$ for all $k \in\{1,2, \ldots, m\}$. Therefore, $F \subset C_{N+1}$ and hence $F \subset C_{n}$ for all $n \in \mathbb{N}$.

Also by induction and using the fact that $\phi(\cdot, x)$ is continuous on $E$ for any $x \in E$, it follows that $C_{k n}$ is closed for each $n \in \mathbb{N}$ and $k \in\{1,2, \ldots, m\}$, and consequently, $C_{n}$ is closed for each $n \in \mathbb{N}$.

We now prove that $C_{n}$ is convex for all $n \in \mathbb{N}$. We observe that $s \in C_{k n}$ is equivalent to $s \in C_{n-1}$ and $\left\|z_{n k}\right\|^{2}-\left\|x_{n}\right\|^{2} \leq 2\left\langle s, j x_{n}-j z_{n k}\right\rangle+\gamma_{k n}$. So the convexity of $C_{k n}$ for each $k \in\{1,2, \ldots, m\}$ and for each $n \in \mathbb{N}$ follows immediately by induction. Thus $C_{n}$ is convex for each $n \in \mathbb{N}$.

We now show that the sequence $\left\{x_{n}\right\}$ converges. Since $\left\{C_{n}\right\}$ is a decreasing sequence of closed, convex subsets of $E$, such that $\bigcap_{n=1}^{\infty} C_{n} \neq \emptyset$, then the Mosco limit $M-\lim _{n \rightarrow \infty} C_{n}$ exists and $M-\lim _{n \rightarrow \infty} C_{n}=\bigcap_{n=1}^{\infty} C_{n}$. By Lemma 2.2, the sequence $\left\{x_{n}\right\}$ converges to $x^{*}:=$ $\prod_{C^{*}} x_{0}$, where $C^{*}=\bigcap_{n=1}^{\infty} C_{n}$.

We observe that

$$
\lim _{n \rightarrow \infty} \gamma_{k n}=0 \quad \text { for each } k \in\{1,2, \ldots, m\}
$$

and from the fact that $\left\{x_{n}\right\}$ is convergent, we easily deduce that

$$
\lim _{n \rightarrow \infty} \phi\left(x_{n+1}, x_{n}\right)=0
$$

Since $x_{n+1} \in C_{n}$, we get that for each $k \in\{1,2, \ldots, m\}, \phi\left(x_{n+1}, z_{k n}\right) \leq \phi\left(x_{n+1}, x_{n}\right)+\gamma_{k n}$, and so from (3.2) and (3.3), we obtain $\lim _{n \rightarrow \infty} \phi\left(x_{n+1}, z_{k n}\right)=0$ for each $k \in\{1,2, \ldots, m\}$. By Lemma 2.1, we get that $\lim _{n \rightarrow \infty}\left\|x_{n+1}-z_{k n}\right\|=0$ and $\lim _{n \rightarrow \infty}\left\|x_{n+1}-x_{n}\right\|=0$. So, for each $k \in\{1,2, \ldots, m\}$,

$$
\left\|x_{n}-z_{k n}\right\| \leq\left\|x_{n+1}-z_{k n}\right\|+\left\|x_{n}-x_{n+1}\right\| \rightarrow 0 \quad \text { as } n \rightarrow \infty
$$

Since $j$ is norm-to-norm uniformly continuous on bounded subsets of $E$, we get that, for each $k \in\{1,2, \ldots, m\}, \lim _{n \rightarrow \infty}\left\|j x_{n}-j z_{k n}\right\|=0$. Using (3.1) we obtain that

$$
\left\|j x_{n}-j T_{1}^{n} x_{n}\right\|=\frac{1}{\left(1-\beta_{1 n}\right)}\left\|j x_{n}-j z_{1 n}\right\| \rightarrow 0 \quad \text { as } n \rightarrow \infty,
$$

and for $k \in\{2,3, \ldots, m\}$,

$$
\left\|j x_{n}-j T_{k}^{n} z_{(k-1) n}\right\|=\frac{1}{\left(1-\beta_{k n}\right)}\left\|j x_{n}-j z_{k n}\right\| \rightarrow 0 \quad \text { as } n \rightarrow \infty
$$

Using these and the fact that $j^{-1}$ is norm-to-norm uniformly continuous on bounded subsets of $E^{*}$, we get

$$
\lim _{n \rightarrow \infty}\left\|x_{n}-T_{1}^{n} x_{n}\right\|=\lim _{n \rightarrow \infty}\left\|x_{n}-T_{2}^{n} z_{1 n}\right\|=\cdots=\lim _{n \rightarrow \infty}\left\|x_{n}-T_{m}^{n} z_{(m-1) n}\right\|=0
$$


Since $x_{n} \rightarrow x^{*}$ as $n \rightarrow \infty$, we obtain that $T_{1}^{n} x_{n} \rightarrow x^{*}, T_{2}^{n} z_{1 n} \rightarrow x^{*}, \ldots, T_{m}^{n} z_{(m-1) n} \rightarrow x^{*}$, as $n \rightarrow \infty$. By the uniform asymptotic regularity of each of the maps $T_{k}, k=1,2, \ldots, m$, we get

$$
\left\|T_{1}^{n+1} x_{n}-x^{*}\right\| \leq\left\|T_{1}^{n+1} x_{n}-T_{1}^{n} x_{n}\right\|+\left\|T_{1}^{n} x_{n}-x^{*}\right\| \rightarrow 0 \quad \text { as } n \rightarrow \infty,
$$

and

$$
\begin{aligned}
\left\|T_{k}^{n+1} z_{(k-1) n}-x^{*}\right\| \leq & \left\|T_{k}^{n+1} z_{(k-1) n}-T_{k}^{n} z_{(k-1) n}\right\| \\
& +\left\|T_{k}^{n} z_{(k-1) n}-x^{*}\right\| \rightarrow 0 \quad \text { as } n \rightarrow \infty,
\end{aligned}
$$

for $k=2,3, \ldots, m$. These imply $T_{1}\left(T_{1}^{n} x_{n}\right) \rightarrow x^{*}$ and $T_{k}\left(T_{k}^{n} z_{(k-1) n}\right) \rightarrow x^{*}$ as $n \rightarrow \infty$, and for $k=2,3, \ldots, m$. By the closedness of each of the maps $T_{k}, k=1,2, \ldots, m$, we have that $x^{*} \in F$.

As $F$ is a nonempty closed convex subset of $C^{*}:=\bigcap_{n=1}^{\infty} C_{n}$, we obtain that $x^{*}=\prod_{F} x_{0}$. This completes the proof.

The conditions of closedness and uniform asymptotic regularity on the maps $\left\{T_{k}\right\}_{k=1}^{m}$ can be replaced by the condition that each of the maps $\left\{T_{k}\right\}_{k=1}^{m}$ is uniformly Lipschitz. So we have the following theorem:

Theorem 3.2 Let $E, C,\left\{T_{k}\right\}_{k=1}^{m}, F,\left\{t_{k n}\right\},\left\{s_{k n}\right\}$, and $\left\{x_{n}\right\}$ be as in Theorem 3.1 with the exception that $\left\{T_{k}\right\}_{k=1}^{m}$ are uniformly $L_{k}, k=1,2, \ldots, m$, Lipschitzian instead of uniformly asymptotically regular and closed. Then the sequence $\left\{x_{n}\right\}$ converges strongly to $x^{*}=\prod_{F} x_{0}$.

Proof The proof that $F \in C_{n}, C_{n}$ is closed, convex for each $n \in \mathbb{N}$ and $\lim _{n \rightarrow \infty} x_{n}=x^{*}$ follows as in Theorem 3.1. Also relations (3.2), (3.3), (3.4) and (3.5) are obtainable as in Theorem 3.1. We only need to show that $x^{*} \in F$. Let $L:=\max _{1 \leq k \leq m} L_{k}$, then using (3.4) and (3.5) we get

$$
\begin{aligned}
\left\|T_{1}^{n} x_{n}-x_{n}\right\| & \leq\left\|T_{1}^{n} x_{n}-T_{1}^{n} z_{1 n}\right\|+\left\|T_{1}^{n} z_{1 n}-x_{n}\right\| \\
& \leq L\left\|x_{n}-z_{1 n}\right\|+\left\|T_{1}^{n} z_{1 n}-x_{n}\right\| \rightarrow 0 \quad \text { as } n \rightarrow \infty,
\end{aligned}
$$

and for $k=2,3, \ldots, m$,

$$
\begin{aligned}
\left\|T_{k}^{n} x_{n}-x_{n}\right\| & \leq\left\|T_{k}^{n} x_{n}-T_{k}^{n} z_{(k-1) n}\right\|+\left\|T_{1}^{n} z_{(k-1) n}-x_{n}\right\| \\
& \leq L\left\|x_{n}-z_{(k-1) n}\right\|+\left\|T_{k}^{n} z_{(k-1) n}-x_{n}\right\| \rightarrow 0 \quad \text { as } n \rightarrow \infty .
\end{aligned}
$$

So we obtain

$$
\begin{aligned}
\left\|T_{1} x_{n}-x_{n}\right\| \leq & \left\|T_{1} x_{n}-T_{1}^{n+1} x_{n}\right\|+\left\|T_{1}^{n+1} x_{n}-T_{1}^{n+1} x_{n+1}\right\| \\
& +\left\|T_{1}^{n+1} x_{n+1}-x_{n+1}\right\|+\left\|x_{n+1}-x_{n}\right\| \\
\leq & L\left\|x_{n}-T_{1}^{n} x_{n}\right\|+L\left\|x_{n}-x_{n+1}\right\| \\
& +\left\|x_{n+1}-T_{1}^{n+1} x_{n+1}\right\|+\left\|x_{n+1}-x_{n}\right\| \rightarrow 0 \quad \text { as } n \rightarrow \infty,
\end{aligned}
$$


and also for $k=2,3, \ldots, m$,

$$
\begin{aligned}
\left\|T_{k} x_{n}-x_{n}\right\| \leq & \left\|T_{k} x_{n}-T_{k}^{n+1} z_{(k-1) n}\right\|+\left\|T_{k}^{n+1} z_{(k-1) n}-T_{k}^{n+1} x_{n}\right\| \\
& +\left\|T_{k}^{n+1} x_{n}-T_{k}^{n+1} x_{n+1}\right\|+\left\|T_{k}^{n+1} x_{n+1}-x_{n+1}\right\|+\left\|x_{n+1}-x_{n}\right\| \\
\leq & L\left\|x_{n}-T_{k}^{n} z_{(k-1) n}\right\|+L\left\|z_{(k-1) n}-x_{n}\right\| \\
& +(1+L)\left\|x_{n}-x_{n+1}\right\|+\left\|x_{n+1}-T_{k}^{n+1} x_{n+1}\right\| \rightarrow 0 \quad \text { as } n \rightarrow \infty .
\end{aligned}
$$

Finally, using these, the fact that $x_{n} \rightarrow x^{*}$ as $n \rightarrow \infty$, and the continuity of $T_{k}$ for each $k$, we obtain that $x^{\prime \prime} \in F$ and this completes the proof.

The following corollaries follow from Theorems 3.1 and 3.2.

Corollary 3.3 Let E be a real uniformly convex and uniformly smooth Banach space and $C$ be a nonempty, bounded, closed and convex subset of $E$. Let $T_{k}: C \rightarrow C, k=1,2,3, \ldots, m$ be a finite family of quasi- $\phi$-asymptptically nonexpansive maps with corresponding sequences $\left\{t_{k n}\right\}, k=1,2,3, \ldots, m$, such that $t_{k n} \rightarrow 1$, as $n \rightarrow \infty$. Let $F=\bigcap_{k=1}^{m} F\left(T_{k}\right) \neq \emptyset$ and let $t_{n}=\max _{1 \leq k \leq m} t_{k n}, n \in \mathbb{N}$. Assume also that the maps $T_{k}, k=1,2, \ldots, m$ are either closed and uniformly asymptotically regular on $C$ or uniformly Lipschitzian on $C$. Let $x_{0} \in C$ be arbitrary and $C_{0}=C$. For $k=1,2, \ldots, m$, let $\left\{\beta_{k n}\right\}$ be sequences in $(a, b)$ for some $a, b \in(0,1)$, $a<b$. Let $\left\{x_{n}\right\}$ be a sequence generated by (3.1). Then the sequence $\left\{x_{n}\right\}$ converges strongly to $x^{*}=\prod_{F} x_{0}$.

Corollary 3.4 Let $E$ be a real uniformly convex and uniformly smooth Banach space and $C$ be a nonempty, bounded, closed and convex subset of $E$. Let $T_{k}: C \rightarrow C, k=1,2,3, \ldots, m$ be a finite family of $\phi$-asymptotically nonexpansive maps with corresponding sequences $\left\{t_{k n}\right\}, k=1,2,3, \ldots, m$, such that $t_{k n} \rightarrow 1$, as $n \rightarrow \infty$. Let $F=\bigcap_{k=1}^{m} F\left(T_{k}\right) \neq \emptyset$ and let $t_{n}=$ $\max _{1 \leq k \leq m} t_{k n}$. Assume also that the maps $T_{k}, k=1,2, \ldots, m$ are either closed and uniformly asymptotically regular on $C$ or uniformly Lipschitzian on $C$. Let $x_{0} \in C$ be arbitrary and $C_{0}=C$. For $k=1,2, \ldots, m$, let $\left\{\beta_{k n}\right\}$ be sequences in $(a, b)$ for some $a, b \in(0,1), a<b$. Let $\left\{x_{n}\right\}$ be a sequence generated by (3.1). Then the sequence $\left\{x_{n}\right\}$ converges strongly to $x^{*}=$ $\prod_{F} x_{0}$.

Corollary 3.5 Let $H$ be a real Hilbert space, $C$ be a nonempty, bounded, closed and convex subset of $H$. Let $T_{k}: C \rightarrow C, k=1,2,3, \ldots, m$ be a finite family of generalized asymptotically quasi-nonexpansive maps with corresponding sequences $\left\{t_{k n}\right\}$ and $\left\{s_{k n}\right\}, k=1,2,3, \ldots, m$ such that $t_{k n} \rightarrow 1$ and $s_{k n} \rightarrow 0$ as $n \rightarrow \infty$. Let $F=\bigcap_{k=1}^{m} F\left(T_{k}\right) \neq \emptyset$ and let $t_{n}=\max _{1 \leq k \leq m} t_{k n}$. Assume also that the maps $T_{k}, k=1,2, \ldots$, m are either closed and uniformly asymptotically regular on $C$ or uniformly $L_{k}, k=1,2, \ldots, m$ Lipschitzian on $C$. Let $x_{0} \in C$ be arbitrary and $C_{0}=C$. For $k=1,2, \ldots, m$, let $\left\{\beta_{k n}\right\}$ be sequences in $(a, b)$ for some $a, b \in(0,1), a<b$. Let 
$\left\{x_{n}\right\}$ be a sequence generated by

$$
\left\{\begin{array}{l}
x_{1}=x_{0} \\
z_{1 n}=\beta_{1 n} x_{n}+\left(1-\beta_{1 n}\right) T_{1}^{n} x_{n}, \\
z_{k n}=\beta_{k n} x_{n}+\left(1-\beta_{k n}\right) T_{k}^{n} z_{(k-1) n}, \quad k=2,3,4, \ldots, m, \\
C_{k n}=\left\{v \in C_{n-1}:\left\|z_{k n}-v\right\|^{2} \leq\left\|x_{n}-v\right\|^{2}+\gamma_{k n}\right\}, \\
C_{n}=\bigcap_{k=1}^{k} C_{k n}, \\
x_{n+1}=P_{C_{n}} x_{0}, \quad n \in \mathbb{N},
\end{array}\right.
$$

where $\gamma_{k n}=\left(t_{n}^{2}-1\right)\left(1-\beta_{k n}\right)\left[1+t_{k n}^{2}\left(1-\beta_{k-1 n}\right)\left[1+t_{(k-1) n}^{2}\left(1-\beta_{(k-2) n}\right) \times\left[1+t_{(k-2) n}^{2}(1-\right.\right.\right.$ $\left.\left.\left.\left.\beta_{(k-3) n}\right)\left[\cdots\left[1+t_{2 n}^{2}\left(1-\beta_{1 n}\right)\right] \cdots\right]\right]\right]\right](\operatorname{diam} C)^{2}+\sum_{i=1}^{k} s_{i n} \prod_{j=i}^{k}\left(1-\beta_{j n}\right) \prod_{l=i+1}^{k} t_{l n}$. Then, the sequence $\left\{x_{n}\right\}$ converges strongly to $x^{*}=P_{F} x_{0}$.

Corollary 3.6 Let $H$ be a real Hilbert space, $C$ be a nonempty,closed and convex subset of $H$. Let $T_{k}: C \rightarrow C, k=1,2,3, \ldots, m$ be a finite family of asymptotically nonexpansive maps with corresponding sequences $\left\{t_{k n}\right\}, k=1,2,3, \ldots, m$, such that $t_{k n} \rightarrow 1$ as $n \rightarrow \infty$. Let $F=\bigcap_{k=1}^{m} F\left(T_{k}\right) \neq \emptyset$ and let $t_{n}=\max _{1 \leq k \leq m} t_{k n}$. Let $x_{0} \in C$ be arbitrary and $C_{1}=C$. For $k=$ $1,2, \ldots, m$, let $\left\{\beta_{k n}\right\}$ be sequences in $(a, b)$ for some $a, b \in(0,1), a<b$. Let $\left\{x_{n}\right\}$ be a sequence generated by (3.10). Then the sequence $\left\{x_{n}\right\}$ converges to $P_{F} x_{0}$.

Remark 3.7 Theorem 3.1 and Corollary 3.5 extend and improve several important recent results. For instance, Corollary 3.5 is an improvement and generalization of Theorem 1.1 and Theorem 3.1 of [20].

Remark 3.8 It is not clear whether Theorem 3.1 and Corollary 3.5 hold without the boundedness assumption on $C$.

Competing interests

The authors declare that they have no competing interest.

Authors' contributions

All the authors contributed equally in writing this article.

\section{Author details}

${ }^{1}$ Department of Mathematical Sciences, Bayero University, Kano, Nigeria. ${ }^{2}$ Mathematics institutes, African University of Science and Technology, Abuja, Nigeria.

\section{Acknowledgements}

This work was conducted when the first author was visiting the Abdus Salam International Center for Theoretical Physics, Trieste, Italy, as an associate. He would like to thank the center for hospitality and financial support.

\section{Received: 10 January 2012 Accepted: 4 July 2012 Published: 23 July 2012}

\section{References}

1. Alber, Y: Metric and generalized projection operators in Banach spaces: properties and applications. In: Karstsatos, AG (ed.) Theory and Applications of Nonlinear Operators of Accretive and Monotone Type, vol. 178, pp. 15-50. Dekker, New York (1996)

2. Alber, Y, Guerre-Delabriere, S: On the projection methods for fixed point problems. Analysis 21, 17-39 (2001)

3. Belluce, LP, Kirk, WA: Fixed point theorem for families of contraction mappings. Pac. J. Math. 18, 213-217 (1966)

4. Chidume, CE, Ali, B: Approximation of common fixed points for finite families of nonself asymptotically nonexpansive mappings in Banach spaces. J. Math. Anal. Appl. 326, 960-973 (2007)

5. Chidume, CE, Ali, B: Convergence theorems for finite families of asymptotically nonexpansive mappings. J. Inequal. Appl. 326, Article ID 68616 (2007). doi:10.1155/2007/68616

6. Das, G, Debata, JP: Fixed points of quasi-nonexpansive mappings. Indian J. Pure Appl. Math. 17, 1263-1269 (1986) 
7. Diaz, JB, Metcalf, FB: On the structure of the set of subsequential limit points of successive approximations. Bull. Am. Math. Soc. 73, 516-519 (1967)

8. Goebel, K, Kirk, WA: A fixed point theorem for asymptotically nonexpansive mappings. Proc. Am. Math. Soc. 35, $171-174(1972)$

9. Ibaraki, T, Kimura, Y, Takahashi, W: Convergence theorems for generalized projections and maximal monotone operators in Banach spaces. Abstr. Appl. Anal. 2003(10), 621-629 (2003)

10. Inchan, I, Plubtieng, S: Strong convergence theorem of hybrid method for two asymptotically nonexpansive mappings in Hilbert spaces. Nonlinear Anal. Hybrid Syst. 2, 1125-1135 (2008)

11. Ishikawa, S: Fixed point theorems for asymptotically nonexpansive mappings. Proc. Am. Math. Soc. 44, 147-150 (1974)

12. Kamimura, S, Takahashi, W: Strong convergence of a proximal type algorithm in Banach space. SIAM J. Optim. 13, 938-945 (2002)

13. Khan, AR, Domlo, AA, Fukhar-ud-din, H: Common fixed point Noor iteration for finite family of asymptotically quasi-nonexpansive mappings in Banach spaces. J. Math. Anal. Appl. 341, 1-11 (2008)

14. Kim, TH, Xu, HK: Strong convergence of modified Mann iterations for asymptotically nonexpansive mappings and semigroups. Nonlinear Anal. 24, 1140-1152 (2006)

15. Kimura, Y, Takahashi, W: On a hybrid method for family of relatively nonexpansive mappings in a Banach space. J. Math. Anal. Appl. 357, 356-363 (2009)

16. Kirk, WA: A fixed point theorem for mappings which do not increase distance. Am. Math. Mon. 72, 1004-1006 (1965)

17. Lim, TC: A fixed point theorem for families of nonexpansive mappings. Pac. J. Math. 53, 487-493 (1974)

18. Mosco, U: Convergence of convex sets and solutions of variational inequalities. Adv. Math. 3, 510-585 (1969)

19. Nakajo, K, Takahashi, W: Strong convergence theorems for nonexpansive mappings and nonexpansive semigroups. J. Math. Anal. Appl. 279, 372-379 (2003)

20. Plubtieng, S, Ughchittrakool, K: Strong convergence of modified Ishikawa iteration for two asymptotically nonexpansive mappings and semigroups. Nonlinear Anal. 67, 2306-2315 (2007)

21. Shahzad, N, Zegeye, $\mathrm{H}$ : Strong convergence of an implicit iteration process for finite family of generalized asymptotically quasi-nonexpansive maps. Appl. Math. Comput. 189, 1058-1065 (2007)

22. Shahzad, $\mathrm{N}$, Udomene, A: Approximating common fixed points of two asymptotically quasi-nonexpansive mappings in Banach spaces. Fixed Point Theory Appl. 2006, Article ID 18909 (2006)

23. Solodov, MV, Svaiter, BF: Forcing strong convergence of proximal point iterations in a Hilbert space. Math. Program. Ser. A 87, 189-202 (2000)

24. Takahashi, W, Takeuchi, Y, Kubota, R: Strong convergence theorems by hybrid methods for families of nonexpansive mappings in Hilbert space. J. Math. Anal. Appl. 241, 276-289 (2007)

25. Takahashi, W, Tamura, T: Convergence theorems for pair of nonexpansive mappings. J. Convex Anal. 5, 45-56 (1998)

26. Wang, L: Strong and weak convergence theorems for common fixed points of nonself asymptotically nonexpansive mappings. J. Math. Anal. Appl. 323, 550-557 (2006)

27. $\mathrm{Xu}, \mathrm{Y}, \mathrm{Z}$ hang, $\mathrm{X}$, Khang, J, Su, Y: Modified hybrid algorithm for family of quasi- $\phi$-asymptotically nonexpansive mappings. Fixed Point Theory Appl. 2010, Article ID 170701 (2010). doi:10.1155/2010170701

28. Zhou, H, Gao, G, Tan, B: Convergence theorems of a modified hybrid algorithm for finite family of quasi- $\phi$-asymptotically nonexpansive mappings. J. Appl. Math. Comput. 32, 453-464 (2010)

doi:10.1186/1687-1812-2012-121

Cite this article as: Ali and Minjibir: Convergence of a hybrid iterative method for finite families of generalized quasi- $\phi$-asymptotically nonexpansive mappings. Fixed Point Theory and Applications 2012 2012:121.

\section{Submit your manuscript to a SpringerOpen ${ }^{\circ}$ journal and benefit from:}

- Convenient online submission

- Rigorous peer review

- Immediate publication on acceptance

- Open access: articles freely available online

- High visibility within the field

- Retaining the copyright to your article 